\title{
Elaboração de estratégias analíticas para a síntese da droga "chá de pilha" e a determinação de metais utilizando a técnica de ICP OES e ICP MS
}

\author{
Raphael N. Delmiglio*, Gustavo S. Pessoa, Marco A. Z. Arruda.
}

\begin{abstract}
Resumo
Este trabalho teve como foco a determinação da quantidade de metais como $\mathrm{Mn}, \mathrm{Co}, \mathrm{Zn}, \mathrm{Ni}, \mathrm{Hg}$ e $\mathrm{Pb}$ presentes na droga de abuso caseira chamada "chá de pilha", onde uma infusão de pilhas (baterias) ${ }^{2}$ é feita, filtrada e depois ingerida. Esta droga vem sendo extensivamente usada por usuários de drogas de baixa renda em momentos de abstinência. Para a realização deste projeto utilizou-se técnicas de 2 importantes áreas da química analítica: o preparo de amostras e a análise por espectrometria de emissão óptica. A extração dos metais na pilha ocorreu por meio de aquecimento de água destilada com o conteúdo interno de pilhas comuns, similar a preparação de um chá convencional. A análise dos metais foi feita utilizando a técnica de ICP OES com padrão interno de Rh e posteriormente confirmada por análise em um equipamento ICP MS. Houve um cuidado na elaboração dos métodos de extração para que não se usasse reagentes de alta toxicidade já que o "chá" depois de elaborado seria consumido pelo usuário da droga em uma situação hipotética. Também foi dada atenção para que fossem usados na elaboração da droga aparelhos e reagentes acessíveis já que esta é uma droga caseira. Obteve-se para concentrações extremamente elevadas em relação a máxima permitida pelo padrão de potabilidade da água exigido pela CETESB nos casos do Mn ( 36 vezes maior que a máxima), Zn (813 vezes maior que a máxima) e Ni (9 vezes maior que a máxima)
\end{abstract}

\section{Palavras-chave:}

Forense, Preparo de Amostras, Espectroanalítica

\section{Introdução}

A droga de abuso caseira chamada "chá de pilha" é extensivamente usada por usuários de drogas de baixa renda como forma de conter a abstinência. Esta droga vem ganhando destaque entre os moradores de rua pois pode ser preparada com uma infusão de pilhas (baterias) que posteriormente é filtrada e depois ingerida. A problemática ocorre no fato de que não se tem conhecimento da composição desta droga nem de seus efeitos fisiológicos no usuário, apenas especula-se a presença de metais pesados com base na composição de uma bateria. Assim quantificar esses metais dará embasamento para o estudo das alterações que essa droga gera no organismo

\section{Resultados e Discussão}

$\mathrm{Na}$ primeira parte deste projeto foi feita a análise da matriz a ser extraída pela infusão (todo o conteúdo interno de uma pilha). Ela foi decomposta totalmente utilizando a decomposição ácida assistida por microondas ${ }^{3}$ e posteriormente analisada em um ICP OES ${ }^{4}$ utilizando padrão interno de Rh. Foi possível quantificar com sucesso apenas $\mathrm{Mn}, \mathrm{Zn}, \mathrm{Ni}$, Co e $\mathrm{Pb}$. Os níveis de $\mathrm{Hg}$ ficaram abaixo do limite de detecção (LD). A quantificação foi verificada utilizando um ICP MS ${ }^{4}$

Na segunda parte foi feita a síntese do "chá" e a análise em um ICP OES ${ }^{4}$ utilizando padrão interno de Rh onde foi possível quantificar $\mathrm{Mn}, \mathrm{Ni}$ e $\mathrm{Zn}$ apenas. Os níveis de $\mathrm{Pb}$ ficaram abaixo do LD e os de Co abaixo do limite de quantificação (LQ). A Tabela 1 mostra os níveis dos metais encontrados no chá e a concentração máxima permitida no padrão de potabilidade de água da CETESB $^{1}$. $\mathrm{Na}$ terceira coluna é explicitado a porcentagem de massa do metal obtida no "chá" em relação a masa total presente na matriz

Tabela 1: Concentração em Água Potável, Concentração na Droga sintetizada e Porcentagem de metal extraído da matriz

\begin{tabular}{|c|c|c|c|}
\hline & Chá (mg/L) & Agua Potável (mg/L) & Porcentagem de extração da Matriz (\%) \\
$\mathrm{Mn}$ & 3,64 & 0,10 & 0,01 \\
$\mathrm{Zn}$ & 4066,71 & 5,00 & 76,76 \\
$\mathrm{Ni}$ & 0,66 & 0,07 & 11,58 \\
$\mathrm{Co}$ & $<\mathrm{LQ}$ & 0,20 & 0,00 \\
$\mathrm{~Pb}$ & $<\mathrm{LD}$ & 0,01 & 0,00 \\
\hline
\end{tabular}

\section{Conclusão}

A infusão de baterias consegue extrair quantidades significativas de $\mathrm{Mn}, \mathrm{Zn}$ e $\mathrm{Ni}$ da matriz. Essas quantidades superam drasticamente os padrões de potabilidade de água da CETESB, sendo necessário mais estudos a respeito dos efeitos fisiológicos desses níveis de concentração no organismo

PIBIC, grupo GEPAM

\section{Agradecimentos}

\footnotetext{
${ }^{1}<$ http://laboratorios.cetesb.sp.gov.br/servicos/informacoes-toxicologicas/>, acessado em 25/03/2015

2 LINDEN, D.; REDDY, T. B. Handbook of batteries. 3ed. New York: McGraw-Hill, 2002

${ }^{3}$ SKOOG, D.A.; WEST, D.M.; HOLLER, F.J. Fundamentos de Química Analítica, Tradução da $8^{\mathrm{a}}$ ed. Norte-Americana, Thomson Learning Ltda, 2006. 992-995

${ }^{4}$ HOLLER, F.J.; SKOOG, D.A.; CROUCH, S.R. Princípios de Análise Instrumental, Tradução da 6 ed. 268 - 315
} 